\title{
Expressão imuno-histoquímica de c-erb-B2 e p53 em carcinomas gástricos
}

\author{
Imunohistochemical expression of c-erb-B2 and p53 in gastric carcinomas
}

Maria Dirlei F. S. Begnami'; Antônio Hugo J. F. M. Campos'; Edaíse Silva²; André Montagnini ${ }^{3}$; Carlos F. Nascimento ${ }^{4}$; Sueli Nonogaki ${ }^{5}$; Fernando Soares ${ }^{6}$

\begin{abstract}
unitermos
Carcinoma gástrico

p53

c-erb-B2

Imuno-histoquímica

Tissue microarray

\section{resumo}

Introdução: Em nosso meio, os carcinomas gástricos ainda são neoplasias bastante freqüentes e responsáveis por altas taxas de mortalidade. Recentemente, têm-se demonstrado a expressão de p53 e a amplificação do gene c-erb-B2 nos carcinomas gástricos. A relevância e o significado biológico destas alterações ainda não foram totalmente estabelecidos. Objetivo: Estudar as expressões imuno-histoquímicas de p53 e c-erb-B2 em 482 casos de carcinomas gástricos. Material e métodos: Foram construídos três blocos de tissue microarray (TMA) utilizando-se duplicatas de 482 casos de carcinomas gástricos. Os cortes foram corados por hematoxilina e eosina (HE), tendo sido feita pesquisa para p53 e c-erb-B2. Foram considerados positivos para p53 os casos com marcação nuclear em mais de $10 \%$ das células tumorais. Para o c-erb-B2 foram considerados positivos os casos com marcação de membrana completa em mais de $10 \%$ das células tumorais. Resultados: A expressão de p53 e c-erb-B2 foi observada em $30 \%$ e $12 \%$ dos casos, respectivamente. Em relação aos tipos histológicos observou-se correlação entre os carcinomas do tipo intestinal e a expressão de c-erb-B2 $(p<0,001)$. A expressão de p53 foi mais freqüente nos carcinomas com mais de $5 \mathrm{~cm}$ de diâmetro $(p=0,036)$. Não foram observadas alterações nas curvas de sobrevida dos pacientes em relação às expressões desses marcadores. Conclusão: Em nosso meio, carcinomas gástricos do tipo intestinal são mais freqüentemente positivos para c-erb-B2 nos tipos intestinais do que nos difusos. A expressão de p53 está associada ao tamanho tumoral. A técnica do TMA é válida e eficiente para o estudo de marcadores imuno-histoquímicos, com forte correlação com os cortes tradicionais de representação do tumor.
\end{abstract}

Introduction: Gastric cancer is one of the commonest cancers in our country being responsible for a high mortality rate. Recently, the expression of $p 53$ and amplification of c-erb-B2 gene have been described in gastric carcinoma. The relevance and biological significance of these findings are not established yet. Objective: The authors investigated p53, c-erb-B2 immunohistochemical expression in 482 cases of gastric carcinomas. Material and methods: Tissue microarray (TMA) blocks were designed using replicate samples of paraffin-embedded tissue from 482 gastric carcinomas. Sections were stained with $\mathrm{HE}$, and antibodies to $p 53$ and c-erb-B2. Cases were considered p53 positive if nuclear staining was detected in $>10 \%$ of the tumor cells. Cases were assessed c-erb-B2 positive if the entire circunference of the cell membrane was stained in $>10 \%$ of the tumor cells. Results: Overall expression of p53 and c-erb-B2 was observed in $30 \%$ and $12 \%$ of gastric carcinomas cases, respectively. Relationship with intestinal type of gastric carcinomas and expression of c-erb-B2 was shown $(p<0.001)$, and expression of $p 53$ was observed in tumors larger than $5 \mathrm{~cm}(p=0.003)$. There was not significant difference in survival curves of patients with gastric cancer in relation to the expression of these markers. Conclusion: Intestinal type of gastric carcinomas in our country are more frequently positive for c-erb-B2 than diffuse type. The expression of $p 53$ is associated with tumor size. The TMA is a valid and efficient way to study immunohistochemical markers, having a high correlation with the full section.

\section{Gastric cancer}

p53

c-erb-B2

Immunohistochemistry

Tissue microarray

\footnotetext{
1. Médicos patologistas do Centro de Tratamento e Pesquisa do Hospital do Câncer A. C. Camargo.

2. Pós-graduanda da Fundação Antônio Prudente.

3. Médico-cirurgião do Departamento de Cirurgia Abdominal do Centro de Tratamento e Pesquisa do Hospital do Câncer A. C. Camargo.

4. Técnico do Laboratório de Patologia Investigativa do Departamento de Anatomia Patológica do Centro de Tratamento e Pesquisa do Hospital do Câncer A. C. Camargo.

5. Pesquisadora científica do laboratório de imuno-histoquímica da divisão de Patologia do Instituto Adolpho Lutz.

6. Diretor do Departamento de Anatomia Patológica do Centro de Tratamento e Pesquisa do Hospital do Câncer A. C. Camargo.
} 


\section{Introducão}

Embora a incidência de câncer gástrico esteja gradativamente diminuindo em muitos países, esta neoplasia ainda é uma das mais freqüentes em nosso meio, com altas taxas de incidência e mortalidade ${ }^{(25)}$. O prognóstico dos carcinomas gástricos não mudou muito nos últimos anos, e é dependente principalmente do estadiamento (TNM) e do grau histológico do tumor. O tratamento dos carcinomas gástricos é eminentemente cirúrgico, e há consenso de que o tipo de excisão cirúrgica é relevante na sobrevida ${ }^{(3)}$.

Nas últimas décadas, muitos estudos têm demonstrado que o desenvolvimento e a progressão dos carcinomas gástricos são decorrentes de alterações genéticas múltiplas ${ }^{(4,8,}$ $43,45)$. Alguns marcadores biológicos como c-erb-B2, CD44, uAP e p53 têm sido associados ao desenvolvimento e à progressão dos carcinomas gástricos ${ }^{(1,3,31,38)}$.

O p53, um gene supressor de tumor, está localizado no cromossomo 17p. Ele codifica uma proteína de 53kDA e tem sido considerado o guardião do genoma. Esse gene exerce importante papel na regulação do ciclo celular, no reparo do DNA e na morte celular por apoptose. Anormalidades no gene p53 são as alterações moleculares mais freqüentemente encontradas nos diversos tipos de neoplasia. Tem-se demonstrado que a maioria das mutações missense do gene p53 causa alterações na conformação da sua proteína, prolongando a sua meia-vida e podendo acumular-se no núcleo das células neoplásicas. Esse acúmulo pode ser detectado através do método de imuno-histoquímica ${ }^{(10,21)}$. Mutações no gene $\mathrm{p} 53$ foram observadas numa variedade de carcinomas, como nos colorretais ${ }^{(44)}$, mamários ${ }^{(33)}$, esofágicos ${ }^{(13)}$ e gástricos ${ }^{(12,22,36)}$. Em carcinomas gástricos, a freqüência de mutações do p53 varia de $4 \%$ a $64 \%$, dependendo principalmente do tipo de técnica utilizada para a detecção. Numerosos trabalhos têm sido realizados na tentativa de se demonstrar a relevância clínica das alterações do p53 nos pacientes com carcinomas gástricos, porém os resultados são controversos em diversos aspectos: a relação entre a expressão de p53 e a diferenciação dos carcinomas (tipos intestinal vs. difuso) ${ }^{(20,36)}$ a associação com pior prognóstico ${ }^{(30)} \mathrm{e}$ a resposta clínica ao tratamento quimioterápico ${ }^{(15,27)}$. Como já mencionado, os resultados da literatura mundial são conflitantes e controversos, e há poucos artigos nacionais que tenham demonstrado a freqüência da expressão de p53 e sua correlação com o prognóstico em carcinomas gástricos ${ }^{(23)}$.

Outro gene muito estudado é o c-erb-B2. Este gene está localizado no cromossomo 17 (17q), codifica um receptor transmembrana de tirosina quinase de $185 \mathrm{kDa}$ e é um membro da família dos receptores dos fatores de crescimento. A amplificação do c-erb-B2 está associada com a superexpressão de sua proteína na membrana das células neoplásicas. Recentemente, anormalidades neste gene têm atraído atenção especial devido ao desenvolvimento de uma nova terapêutica adjuvante contra o câncer mamário usando um anticorpo monoclonal para os produtos do gene c-erb-B2 (Herceptin ${ }^{\circledR}$; Genentech, Inc., South San Francisco, CA). Estudos têm demonstrado que o c-erb-B2 está superexpresso em outros tipos de carcinoma, como nos ovarianos ${ }^{(42)}$, colônicos ${ }^{(7)}$ e de glândulas salivares ${ }^{(7)}$. Nos carcinomas gástricos, a superexpressão de c-erb-B2 tem sido encontrada predominantemente nos carcinomas bem diferenciados, do tipo intestinal de Lauren, e parece ser um marcador de pior prognóstico(46, 47). Portanto, vimos que alterações genéticas associadas aos oncogenes e genes supressores de tumor, como c-erb-B2 e p53, têm sido descritas nos carcinomas gástricos. Sendo assim, nosso trabalho tem como principal objetivo determinar a freqüência da expressão dessas proteínas através da técnica de imuno-histoquímica em tissue microarrays (TMAs) contendo amostras de 482 casos de carcinomas gástricos operados em nossa instituição e verificar se essas expressões têm alguma associação com o prognóstico.

\section{Material e métodos}

\section{Casuística}

Foram selecionados 482 casos de carcinomas gástricos submetidos a gastrectomia total ou parcial no período de 1988 a 1998, obtidos nos arquivos da anatomia patológica do Centro de Tratamento e Pesquisa do Hospital do Câncer A. C. Camargo. Foram resgatadas todas as respectivas lâminas e blocos de parafina. Blocos representativos do tumor foram selecionados e novos cortes realizados. A revisão da lâmina permitiu o diagnóstico histológico da neoplasia de acordo com a classificação de Lauren ${ }^{(19)}$. A série foi constituída por 234 carcinomas do tipo intestinal, 166 do tipo difuso, 60 mistos e 22 casos representados principalmente por carcinomas do tipo indiferenciado (sólidos) que apresentavam características morfológicas distintas que não permitiam a sua classificação nos tipos histológicos descritos por Lauren e foram chamados de não-classificados. O seguimento clínico foi feito a partir da data da cirurgia por cinco anos (60 meses) ou até a data do óbito. 


\section{Construção do TMA}

Os TMAs foram construídos utilizando-se somente carcinomas gástricos. Os casos foram resgatados do arquivo de anatomia patológica e blocos representativos do tumor foram separados. Lâminas de hematoxilina e eosina (HE) foram utilizadas para a identificação das áreas usadas nos TMAs através de marcações circulares das regiões mais representativas do tumor. Usando o tissue microarrayer (Beecher Instrument, Silver Springe, MD) as áreas de interesse previamente marcadas nas lâminas e identificadas nos blocos doadores foram retiradas e transferidas para os blocos receptores. Para cada caso foram retirados dois cilindros de $0,6 \mathrm{~mm}$ (cores) de duas áreas distintas do tumor, gerando um total de 964 cores. Os cores foram então distribuídos em três blocos ( $\mathrm{A}, \mathrm{B}$ e $\mathrm{C})$ contendo, respectivamente, 176, 105 e 201 casos.

\section{Imuno-histoquímica}

As reações imuno-histoquímicas foram realizadas em dois cortes de níveis diferentes de cada bloco de TMA pela técnica de complexo estreptavidina-biotina-peroxidase (StreptABC, Dako ${ }^{\circledR}$ ). Resumidamente, as lâminas foram previamente revestidas por solução de silano (APTS - Sigma ${ }^{\circledR}$ A3648) diluído a $4 \%$ em acetona. Os cortes obtidos tinham $3 \mu \mathrm{m}$ de espessura após microtomia mecânica. Eles foram desparafinizados e preparados por passagens sucessivas por xilol e etanol e submetidos à recuperação antigênica pelo calor com irradiação por panela de pressão (Eterna, Nigro), utilizando-se tampão citrato $10 \mathrm{mM}, \mathrm{pH} 6$, por 15 minutos. O bloqueio da peroxidase endógena foi realizado com solução de peróxido de hidrogênio a 3\% seguida da incubação com os anticorpos primários p53 (anticorpo monoclonal, clone DO7, 1:100, Dako, USA) e c-erb-B2 (anticorpo policlonal, 1:500, Dako, USA). As reações foram reveladas com solução de diaminobenzidina $\left(\mathrm{DAB}\right.$, Sigma $^{\circledR}$ ) a $60 \mathrm{mg} \%$ e contracoradas com hematoxilina de Harris $\left(\right.$ Merck $\left.^{\circledast}\right)$. Para cada reação utilizou-se como controle positivo tecido sabidamente positivo para o anticorpo testado. Dois controles negativos foram também usados, sendo o primeiro deles pelo não-uso do anticorpo primário, e o segundo, através da retirada do anticorpo secundário durante os passos da reação.

Os casos foram considerados positivos para $\mathrm{p} 53$ quando a coloração marrom foi detectada, nos núcleos das células tumorais, em mais de $10 \%$ das células. Para a avaliação da marcação do c-erb-B2 foi utilizado o escore recomendado pela Dako para a avaliação do Herceptest (Tabela 1).

Padrão de imunomarcação e escores utilizados para a avaliação de

Tabela 1

\begin{tabular}{ccc}
\hline Escore & $\begin{array}{c}\text { Expressão } \\
\text { da proteína }\end{array}$ & $\begin{array}{c}\text { Padrão de imunomarcação } \\
\text { das células neoplásicas }\end{array}$ \\
0 & Negativa & $\begin{array}{c}\text { Marcação ausente ou } \\
\text { presente em menos de 10\% } \\
\text { das células neoplásicas }\end{array}$ \\
\hline $1+$ & Negativa & $\begin{array}{c}\text { Marcação de membrana } \\
\text { fraca e parcial em mais } \\
\text { de 10\% das células }\end{array}$ \\
\hline $2+$ & Positiva & $\begin{array}{r}\text { Marcação completa da } \\
\text { membrana, fraca ou moderada } \\
\text { em mais de 10\% das células }\end{array}$ \\
\hline $3+$ & Positiva & $\begin{array}{c}\text { Marcação completa e } \\
\text { forte da membrana em mais } \\
\text { de 10\% das células }\end{array}$ \\
\hline
\end{tabular}

Para as análises estatísticas foram considerados somente dois grupos: positivos $(2+$ e $3+$ ) e negativos $(1+$ e 0$)$.

\section{Validação do TMA}

Para a validação dos blocos de TMA foi realizado estudo imuno-histoquímico para p53 em lâminas de cortes histológicos tradicionais de 118 casos de carcinomas gástricos contendo áreas extensas de tumor. Esses casos foram escolhidos aleatoriamente e estavam também representados nos blocos de TMA.

\section{Análise estatística}

As análises estatísticas foram feitas utilizando-se 0 programa de computador SPSS 10.0 (SPSS Inc.,Chicago, IL, USA). Para a análise da associação entre dois grupos foi utilizado o teste qui-quadrado ou o teste exato de Fisher. Foram considerados significantes os valores de alfa $<0,05$. As curvas de sobrevida foram estimadas usando-se o método de Kaplan-Meier.

\section{Resultados}

Os principais dados demográficos dos carcinomas gástricos estudados podem ser vistos na Tabela 2. A idade dos 482 pacientes variou de 26 a 84 anos (média de 61,7; mediana de 64 anos). Pacientes do sexo masculino representavam $64 \%$, enquanto $36 \%$ pertenciam ao feminino. Os 
tumores eram preferencialmente localizados na região distal do estômago (87\%) em relação à região proximal (17\%), e $75 \%$ deles apresentavam metástases em linfonodos. Os tumores mediam de 0,6 a $19 \mathrm{~cm}$, sendo que $70 \%$ deles eram maiores que $5 \mathrm{~cm}$. De todos os casos, 455 (94\%) eram tumores que infiltravam a camada muscular própria, a subserosa e a serosa além dessa. Os carcinomas superficialmente invasivos (com infiltração de mucosa e submucosa) eram representados por apenas 27 casos (6\%).

Em relação aos tipos histológicos observou-se predomínio do tipo intestinal (48,5\%), seguido pelos difusos (34\%) e mistos (12\%). Apenas 4,5\% dos carcinomas foram não-classificados.

A freqüência de expressão dos anticorpos pesquisados e as correlações com os principais dados histopatológicos podem ser vistas na Tabela 3. Todas as lâminas de TMA utilizadas para os dois marcadores continham pelo menos

Tabela 2

Principais caracteristicas demográficas e histopatológicas dos casos e expressão imuno-

\begin{tabular}{|l|c|c|}
\hline Tabela 2 & histoquímica de c-erb-B2 e p53 \\
\hline Variáveis & Categoria & $\begin{array}{c}\text { Número de } \\
\text { casos (\%) }\end{array}$ \\
\hline Sexo & Masculino & $308(64)$ \\
& Feminino & $174(36)$ \\
\hline Idade & $<60$ anos & $185(38)$ \\
\hline Tamanho & $>60$ anos & $297(62)$ \\
\hline do tumor & $<5 c m$ & $160(30)$ \\
\hline Localização & $>5 c m$ & $322(70)$ \\
\hline & Proximal & $64(13)$ \\
\hline Nível de & Distal & $417(87)$ \\
\hline infiltração & Superficial & $27(6)$ \\
\hline Metástases em & Profunda & $455(94)$ \\
\hline linfonodos & Positivo & $359(75)$ \\
\hline \multirow{2}{*}{ Tipo } & Negativo & $119(25)$ \\
\hline histológico & Intestinal & $234(48,5)$ \\
\hline Lauren & Difuso & $166(34)$ \\
\hline & Misto & $60(12)$ \\
\hline c-erb-B2 & Não-classificados & $22(4,5)$ \\
\hline p53 & Negativo & $406(88)$ \\
\hline & Positivo & $56(12)$ \\
\hline & Negativo & $321(70)$ \\
\hline
\end{tabular}

$90 \%$ dos casos, com uma representação mínima de 10\% da área tumoral (Figura 1).

A pesquisa de c-erb-B2 foi analisada em 462 (96\%) do total de 482 casos presentes no TMA. Em 20 casos a avaliação do marcador não foi possível devido à representação inadequada do tumor na amostra. Dos 462 casos analisados, somente 56 (12\%) foram positivos, mostrando marcação de membrana 2+ ou 3+ (Figura 2). Foi observada uma correlação estatística entre a expressão de c-erb-B2 e o tipo histológico. Quarenta e nove casos do tipo intestinal, cinco do tipo difuso e dois do misto foram positivos para este marcador; portanto os carcinomas do tipo intestinal, em relação aos demais tipos, foram mais freqüentemente positivos para c-erb-B2 $(p<0,001)$. As demais variáveis como sexo, localização da lesão, metástases em linfonodos e profundidade de infiltração da parede não mostraram associação com a expressão de c-erb-B2.

Em relação à expressão de p53 foram analisados 458 casos (95\%). Vinte e quatro casos (5\%) foram excluídos devido à representação inadequada na amostra. Do total de 458 casos analisados, 137(30\%) mostraram marcação nuclear para o 553 (Figura 2). A maioria dos casos positivos, 79/137 (62\%), era de tumores com mais de $5 \mathrm{~cm}$ de diâmetro máximo, observando-se correlação estatística entre o tamanho tumoral e a expressão de p53 $(p=0,036)$. Não foram observadas associações entre sexo, idade, localização, nível de infiltração e metástases em linfonodos em relação à expressão da proteína $\mathrm{p} 53$. No tocante aos tipos histológicos, observamos imunomarcação em 80 casos do tipo intestinal, 36 do tipo difuso, 17 do tipo misto e quatro nãoclassificados. Apesar da maior freqüência de positividade nos carcinomas do tipo intestinal, a análise dos resultados não mostrou associação estatística.

As curvas de probabilidade de sobrevida acumulada dos 482 casos de carcinomas gástricos em função da expressão de c-erb-B2 e p53 podem ser vistas nas Figuras 3 e 4 . Não foram observadas alterações significativas na sobrevida dos pacientes em relação à expressão destas proteínas.

\section{Comparação entre os resultados da expressão de p53 nos cortes tradicionais e no TMA}

Para validar os resultados obtidos das expressões de $\mathrm{p} 53$ e c-erb-B2 nos TMAs, comparamos as porcentagens dos carcinomas positivos para p53 em uma amostra aleatória de 118 casos de carcinomas gástricos representados por cortes tradicionais. As reações imuno-histoquímicas foram feitas com o mesmo protocolo e utilizando-se o mesmo anticorpo 
Tabela 3

\section{Correlaçōes entre expressão de c-erb-B2, p53 e dados histopatológicos}

\begin{tabular}{|c|c|c|c|c|c|c|c|}
\hline \multicolumn{2}{|c|}{ Variáveis } & \multicolumn{3}{|c|}{ c-erbB-2 } & \multicolumn{3}{|c|}{ p53 } \\
\hline & & Negativo & Positivo & $\mathrm{p}$ & Negativo & Positivo & $\mathrm{p}$ \\
\hline \multirow{2}{*}{ Sexo } & Masculino & $260(88 \%)$ & $33(11 \%)$ & NS & $194(67 \%)$ & $96(33 \%)$ & NS \\
\hline & Feminino & $146(86 \%)$ & $23(14 \%)$ & & $127(75 \%)$ & $41(25 \%)$ & \\
\hline \multirow{2}{*}{ Idade } & $<60$ anos & $159(88 \%)$ & $21(12 \%)$ & NS & $125(70 \%)$ & $52(30 \%)$ & NS \\
\hline & $>60$ anos & $247(88 \%)$ & $35(12 \%)$ & & $196(70 \%)$ & $85(30 \%)$ & \\
\hline \multirow{2}{*}{ Tamanho do tumor } & $<5 \mathrm{~cm}$ & $129(87 \%)$ & $20(13 \%)$ & NS & $91(61 \%)$ & $58(39 \%)$ & 0,036 \\
\hline & $>5 \mathrm{~cm}$ & $277(88 \%)$ & $36(12 \%)$ & & $230(74 \%)$ & $79(26 \%)$ & \\
\hline \multirow{2}{*}{ Metástase em linfonodo } & Negativo & $98(85 \%)$ & $18(15 \%)$ & NS & $81(71 \%)$ & $33(29 \%)$ & NS \\
\hline & Positivo & $305(89 \%)$ & $37(11 \%)$ & & $238(70 \%)$ & $102(30 \%)$ & \\
\hline \multirow{2}{*}{ Localização } & Proximal & $50(80 \%)$ & $13(20 \%)$ & NS & $43(69 \%)$ & $20(31 \%)$ & NS \\
\hline & Distal & $355(89 \%)$ & $43(11 \%)$ & & $278(70 \%)$ & $116(30 \%)$ & \\
\hline \multirow{2}{*}{ Nível de infiltração } & Superficial & $19(80 \%)$ & $5(20 \%)$ & NS & $12(52 \%)$ & $11(48 \%)$ & NS \\
\hline & Profundo & $387(89 \%)$ & $51(11 \%)$ & & $309(71 \%)$ & $126(29 \%)$ & \\
\hline \multirow{4}{*}{ Tipo histológico } & Intestinal & $177(78 \%)$ & $49(22 \%)$ & & $146(65 \%)$ & $80(35 \%)$ & \\
\hline & Difuso & $154(97 \%)$ & $5(3 \%)$ & $<0,001$ & $118(77 \%)$ & $36(23 \%)$ & NS \\
\hline & Misto & $54(97 \%)$ & $2(3 \%)$ & & $40(70 \%)$ & $17(30 \%)$ & \\
\hline & Não-classificados & $21(100 \%)$ & & & $17(81 \%)$ & $4(19 \%)$ & \\
\hline
\end{tabular}

NS = não significativo; $p=$ nivel descritivo do teste de associação

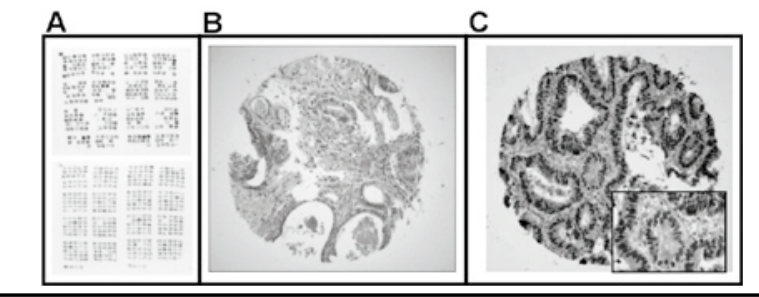

Figura 1 - Design do TMA. Distribuição dos cilindros dos cores do TMA (A). Preservação da morfologia em um dos cilindros de carcinoma do tipo intestinal, corado pela técnica do H\&E (B). Preservação dos antígenos corados pelo p53 (C), tamanho original $\times 40$, detalhe, $\times 600$

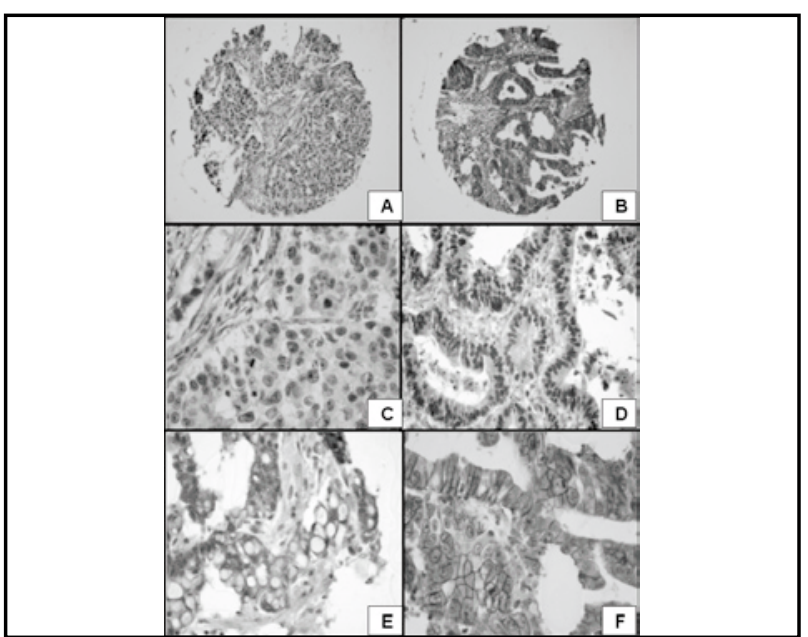

Figura 2 - Marcação nuclear para p53 observada em carcinomas do tipo difuso $(A, C)$ tamanho original $40 x, 600 x$, e em carcinomas do tipo intestinal $(B, D)$, tamanho original 40x,600x. Positividade para c-erbB-2 nos carcinomas do tipo difuso (E) e intestinal (F), tamanho original $600 x$

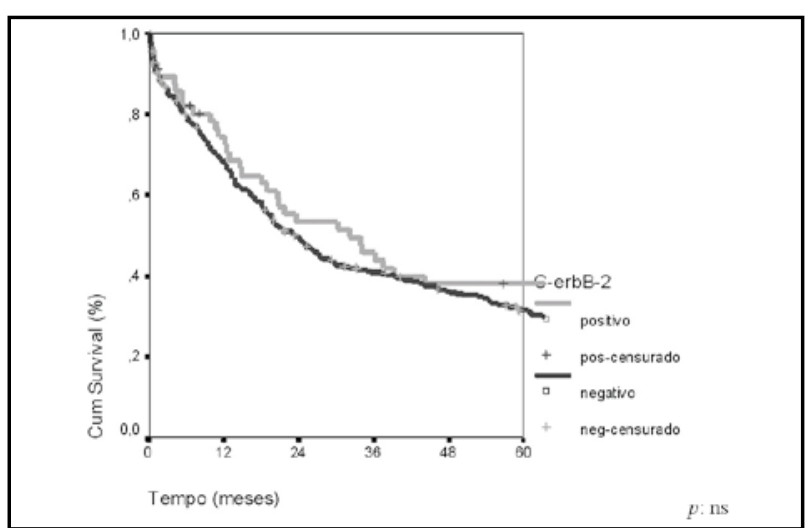

Figura 3 - Curva da sobrevida global dos pacientes com carcinomas gástricos em relação a expressão de c-erb-B2

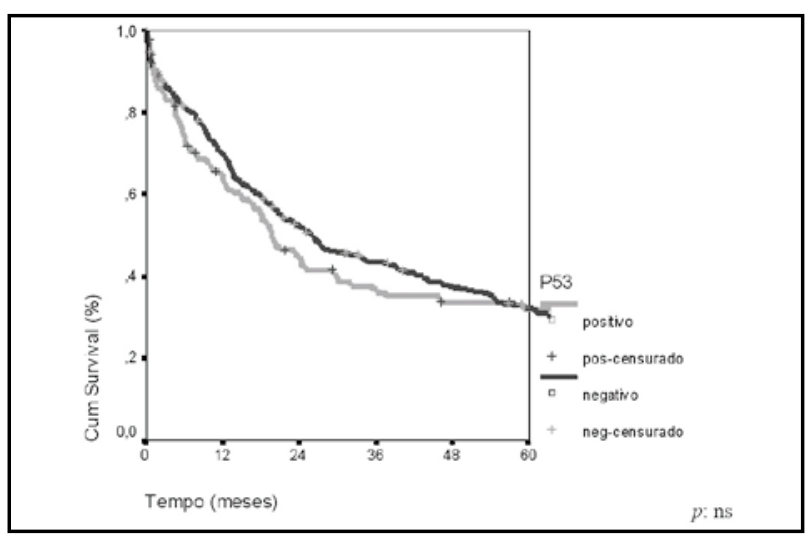

Figura 4 - Curva da sobrevida global dos pacientes com carcinomas gástricos em relação a expressão de p53 
monoclonal para o p53 em todas as lâminas estudadas. Dos 118 casos de carcinomas gástricos representados por cortes tradicionais, 38 (32\%) foram positivos para p53 e, nos TMAs, dos 458 carcinomas gástricos analisados, 137 (30\%) foram positivos para este marcador. Observou-se que a freqüência de expressão de p53 foi muito semelhante entre os dois grupos (corte tradicional vs. TMA), não havendo diferença estatisticamente significante entre a expressão de p53 e o tipo de amostragem do tumor.

\section{Discussão}

O presente estudo demonstrou a freqüência das expressões de c-erb-B2 e p53 em amostras de carcinomas gástricos da população brasileira. No nosso estudo, os carcinomas gástricos expressaram c-erb-B2 em cerca de $12 \%$ dos casos. Essa mesma freqüência de expressão foi observada pela primeira vez por Yonemura et al., em 1991, e tem sido confirmada por outros autores $(17,40,46)$. Observamos também que os casos positivos para esta proteína são predominantemente do tipo intestinal, o que está de acordo com alguns autores, que demonstraram que as alterações genéticas do gene c-erb-B2 ocorrem comumente nos carcinomas gástricos bem diferenciados, do tipo intestinal ou tubular, e estão associadas a mutação do gene c-Ki-ras ${ }^{(16,28,}$ 40). Portanto, algumas anormalidades genéticas podem influenciar a carcinogênese dos diferentes tipos de carcinomas gástricos, e a expressão de c-erb-B2 pode ter importante papel como marcador de diferenciação gástrica.

A superexpressão da proteína c-erb-B2 no nosso estudo não mostrou associação com o estádio clinicopatológico e com o status linfonodal. Esses achados são diferentes de estudos anteriores, que mostraram correlação entre a expressão de c-erb-B2 e o nível de infiltração e metástases $^{(26)}$.

Alterações genéticas no gene p53 são freqüentemente observadas em diferentes tipos de tumor ${ }^{(14)}$. A proteína mutante p53 está associada ao alto risco de metástases em linfonodos e à resistência a drogas pela inibição da apoptose. É demonstrado na literatura que a mutação do gene p53 é um evento precoce na carcinogênese gástrica, sendo detectada através do método de imuno-histoquímica em cerca de 19\%-29\% dos casos de carcinomas gástricos ${ }^{(14,32)}$. Nossos dados mostraram maior freqüência de expressão de p53 nos tumores maiores que $5 \mathrm{~cm}$, sugerindo que a mutação de 553 pode ser um evento tardio no desenvolvimento do carcinoma gástrico. A correlação com o prognóstico ainda não é clara, e a literatura mostra resultados bastante diferentes ${ }^{(41)}$. No nosso estudo demonstramos a expressão da proteína p53 em 30\% dos casos, a maioria em tumores avançados, com discreto predomínio nos carcinomas do tipo intestinal.

O presente estudo foi realizado através do método do tissue microarray, que permite a análise da expressão de diversas proteínas num grande número de casos. A crítica que cabe a este método é a representatividade do tumor, uma vez que a área representada é pequena e os tumores podem apresentar grande heterogeneidade ${ }^{(18,39)}$. Para amenizar estes problemas e tornar o TMA o mais representativo possível do tumor original, os blocos têm sido construídos em duplicatas ${ }^{(6,9,29)}$. Em nosso estudo, com o objetivo de validar os TMAs, realizamos a pesquisa de p53 em uma amostra de 118 casos de carcinomas gástricos em seu corte tradicional. Observamos que a freqüência da expressão desta proteína foi de $32 \%$ nos cortes tradicionais e de $30 \%$ nos de TMA, sendo portanto muito semelhantes. As análises estatísticas não mostraram diferenças significativas entre os dois métodos de representação do tumor em relação à expressão de p53. Nos últimos anos, muitos autores têm demonstrado a contribuição do uso de TMA na pesquisa de marcadores imuno-histoquímicos ou de outras técnicas como hibridização in situ por fluorescência (FISH) ou co-

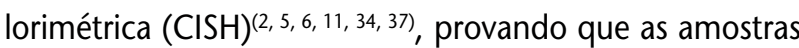
de TMA são representativas do tumor e que os resultados foram estatisticamente semelhantes ao método tradicional de cortes histológicos do tumor, na sua totalidade em lâminas individuais. O nosso estudo foi feito utilizando-se três blocos de TMA, todos com casos em duplicata. Notamos perda em torno de $5 \%$ dos casos na análise das expressões do p53 e do c-erb-B2 pela não-representação do material nas lâminas do TMA. Essa freqüência está de acordo com a literatura, onde pesquisadores da área consideram aceitável a não-representação de até $30 \%$ dos casos em cada lâmina. Portanto, o nosso estudo mostrou que o método TMA é eficaz e permitiu a análise de mais de $90 \%$ dos casos.

Em relação ao prognóstico ainda não estão claras a relação da expressão de p53, a amplificação e a expressão do c-erb-B2 nos carcinomas gástricos. Pinto de Sousa et al. (2004) demonstraram que a expressão de p53 está associada a mau prognóstico ${ }^{(31)}$, porém outros trabalhos na literatura não mostraram esta associação(24). Alguns autores observaram que a expressão de c-erb-B2 está relacionada à doença avançada e pode ser considerada um fator preditivo independente ${ }^{(35)}$. Em nosso estudo, as expressões de p53 e de c-erb-B2 não mostraram associações com o status linfonodal e não influenciaram a sobrevida de pacientes com 
carcinomas gástricos. Portanto, de acordo com os nossos dados, a contribuição do c-erb-B2, bem como do p53, para a carcinogênese gástrica ainda é muito pequena.

Concluindo, demonstramos que a expressão de p53 e c-erb-B2 em carcinomas gástricos de nossa população é de $30 \%$ e $12 \%$, respectivamente. A expressão de c-erb-B2 está associada aos carcinomas do tipo intestinal, e em relação ao prognóstico não observamos associações entre as expressões do dois marcadores e a sobrevida dos pacientes. A técnica do TMA é válida e eficiente para o estudo de marcadores imuno-histoquímicos, com forte correlação com os cortes tradicionais de representação do tumor.

\section{Referências}

I. ALBINO, A. P. et al. Amplification of HER-2/neu gene in human gastric cancer: correlation with primary site. Eur J Surg Oncol, v. 21 , p. 56-60, 1995

2. ALKUSHI, A. et al. Immunoprofile of cervical and endometrial adenocarcinomas using tissue microarray. Virchows Arch, v. 442, p. 27I-7, 2003.

3. ALLGAYER, H.; HEISS, M. M.; SCHILDBERG, F.W. Prognostic factors in gastric cancer. Br J Surg, v. 84, p. I65 I-64, 1997.

4. BECKER, K. F. et al. E-cadherin gene mutations provide clues to diffuse type gastric carcinomas. Cancer Res, v. 54, p. 384552, 1994.

5. CALLAGY, G. et al. Molecular classification of breast carcinomas using tissue arrays. Diag Mol Pathol, v. 12, p. 27-34, 2003.

6. CAMP, R. L.; CHARETTE, L. A.; RIMM, D. L. Validation of tissue microarray technology in breast carcinoma. Lab Invest, v. 80, p. 1943-9, 2000.

7. COHEN, J. A. et al. Expression pattern of the neu (NGL) geneencoded growth factor protein ( $/ 85 n e u$ ) in normal and transformed epithelial tissues of the digestive tract. Oncogene, v. 4, p. 8I-8, 1989.

8. CORREA, P; SHIAO, Y-H. Phenotypic and genotypic events in gastric carcinogenesis. Cancer Res, v. 54, p. 194I-3, 1994.

9. GANCBERG, D. et al. Reliability of the tissue microarray based FISH for evaluation of the HER-2 oncogene in breast carcinoma.J Clin Pathol, v. 55, p. 315-7, 2002.

I0. GANNON, J. V. et al. Activating mutations in p53 produce a common conformational effect. A monoclonal antibody specific for the mutant form. EMBO J, v. 9, p. I595-602, 1990.

I I. GULMANN, C. et al. Biopsy of a biopsy: validation of immunoprofiling in gastric cancer biopsy tissue microarrays. Histopathology, v. 42, p. 70-6, 2003.

12. HAMADA, M. et al. The gene p53 is a potent determinant of chemosensitivity and radiosensitivity in gastric and colorectal cancers. J Cancer Res Clin Oncol, v. I22, p. 360-5, 1996.

13. HASHIMOTO, N. et al. Expression of p53 and RB proteins in squamous cell carcinoma of the esophagus: their relationship with clinicopathologic characteristics. Ann Surg Oncol, v. 6, p. 489-94, 1999.

14. HOLLSTEIN, M. et al. p53 mutation in human cancers. Science, v. 53, p. 253-49, 1991

15. HOSAKA, N. et al. Correlation of immunohistochemical p53 labeling index with inhibition rate in chemosensitivity test in gastric and colon cancer. Anticancer Res, v. 21 , p. 229-35, 2001 .
16. KIHANA, T. et al. Point mutation of c-Ki-ras oncogene in gastric adenoma and adenocarcinoma with tubular differentiation. Jon J Cancer Res, v. 14, p. 82-308, 1991.

I7. KIMURA, M. et al.A proposal for diagnostically meaningful criteria to classify increased epidermal growth factor receptor and c-erb-B2 gene copy numbers in gastric carcinoma, based on correlation of fluorescence in situ hybridization and immunohistochemical measurements. Virchows Arch, v. 445 , p. 255-62, 2004

18. KONONEN, J. et al. Tissue microarrays for high-throughput molecular profiling of tumor specimens. Nat Med, v. 4, p. 844-7, 1998.

19. LAUREN, P.The two histological main types of gastric carcinoma. Diffuse and so-called intestinal type carcinoma: an attempt at histoclinical classification. Acta Pathol Microbiol Scand, v. 64, p. 31-49, 1965.

20. LEE,W.J. et al. Overexpression of $\mathrm{p} 53$ predicts shorter survival in diffuse type gastric cancer. Br J Surg, v. 85, p. I I 38-42, 1998.

21. LEVINE, A. J. et al.The role of the $p 53$ tumour-suppressor gene in tumorigenesis. Br J Cancer, v. 69, p. 409-16, 1994.

22. MAEHARA, Y. et al. Prognostic value of p53 protein expression for patients with gastric cancer- a multivariate analysis. $\mathrm{Br} J$ Cancer, v. 79, p. |255-61, 1999.

23. MATTAR, R. et al. P53 and Rb tumor suppressor gene alterations in gastric cancer. Rev Hosp Clin Fac Med São Paulo, v. 59, p. 172-80, 2004.

24. MCCULLOCH, P. et al. C-erb-B2 and p53 expression are not associated with stage progression of gastric cancer in Britain and Japan. Eur J Surg Oncol, v. 23, p. 304-9, 1997.

25. MINISTÉRIO DA SAÚDE. Secretaria Nacional de Assistência à Saúde. Instituto Nacional do Câncer. Estimativa da incidência e mortalidade por câncer no Brasil. Rio de Janeiro: INCA; 2005.

26. MIZUTANI,T. et al. Relationship of c-erb-B2 protein expression and gene amplification to invasion and metastasis in human gastric cancer. Cancer, v. 72, p. 2083-8, 1993.

27. NAKATA, B. et al. $\mathrm{P} 53$ protein overexpression as a predictor of the response to chemotherapy in gastric cancer. Surg Today, v. 28, p. 595-8, 1998.

28. NAKJIMA, M. et al.The prognostic significance of amplification and overexpression of c-met and c-erb-B2 in human gastric carcinomas. Cancer, v 85, p. 1894-902, 1999.

29. NOCITO, A. et al. Microarray of bladder cancer tissue is highly representative of proliferation index and histological grade. 
J Pathol, v. 194, p. 349-57, 2001.

30. PINTO DE SOUSA J. et al. Clinicopathological significance and survival influence of $\mathrm{p} 53$ protein expression in gastric carcinoma. Histopathology, v. 44, p. 323-3I, 2004.

31. PINTO DE SOUZA J. et al. Mucins MUCI, MUC2, MUC5AC and MUC6 expression in the evalution of differentiation and clinicobiological behavior of gastric carcinoma. Virchows Arch, v. 440, p. 304-10, 2002.

32. RANZANI, G. N. et al. p53 gene mutations and protein nuclear accumulation are early events in intestinal type gastric cancer but late events in diffuse type. Cancer Epidemiol Biomarkers Prev, v. 4, p. 223-31, 1995.

33. REED, W. et al. The prognostic value of $p 53$ and c-erb-B2 immunostaining is overrated for patients with lymph node negative breast carcinoma: a multivariate analysis of prognostic factors in 613 patients with a follow-up of $14-30$ years. Cancer, v. 88, p. 804-13, 2000.

34. REIS-FILHO, J. S. et al. Distribution of p63, cytokeratins $5 / 6$ and cytokeratin 14 in 51 normal and 400 neoplastic human tissue samples using TARP-4 multi-tumor tissue microarray. Virchows Arch, v. 443, p. 122-32, 2003.

35. ROSS, J. S.; MCKENNA, B. J. The HER-2/ neu oncogene in tumors of the gastrointestinal tract. Cancer Investigation, v. 19, p. 554-68, 2001.

36. ROVIELLO F et al. p53 accumulation is a prognostic factor in intestinal-type gastric carcinoma but not in the diffuse type. Ann Surg Oncol, v.6, p. 739-745, 1999.

37. RUBIN, M. A. et al. Tissue microarray sampling strategy for prostate cancer biomarker analysis. Am J Surg Pathol, v. 26, p. 312-9, 2002.

38. SAITO, H. et al. Serum concentration of CD44 variant 6 and its relation to prognosis in patients with gastric carcinoma. Cancer, v. 83, p. 1094-101, 1998.

39. SCHRAML P. et al. Tissue microarrays for gene amplification surveys in many different tumor types. Clin Cancer Res, v. 5, p. 1966-75, 1999.

40. SERUCA, L. D. et al. C-erb-B2 expression in primary gastric carcinomas and their metastases. Mod Pathol, v. 5, p. 38490, 1992.

4I.SHEPHERD,T. et al.Alterations in exon 4 of the $\mathrm{p} 53$ gene in gastric carcinoma. Gastroenterology, v. I I 8, p. I039-44, 2000.

42. SALMÓN, D. J. et al. Studies of HER-2/neu proto-oncogene in human breast and ovarian cancer. Science, v. 244, p. 707-12, 1989.

43. TAHARA, E. Genetic alterations in human gastrointestinal cancers. Cancer, v. 75, p. 1410-7, 1995.

44.WONG,S. et al.Mutant plasma 553 protein levels: prognostications in colorectal carcinoma. Br J Surg, v. 84, p. 664-5, 1997.

45. WRIGHT, P. A. et al. Molecular pathology of gastric carcinoma: progress and prospects. Hum Pathol, v. 2, p. 848-59, 1992.

46. YONEMURA, Y. et al. Expression of c-erb-B2 oncoprotein is an independent indicator of poor short- term prognosis in patients with gastric carcinoma. Cancer, v. 67, p. 29|4-8, 1991.

47.YONEMURA, Y. et al. Evaluation of immunoreactivity for erbB2 protein as a marker of poor short term prognosis in gastric cancer. Cancer Res, v. 5 I, p. I034-8, I 991. 